\title{
Lack of reciprocity and strain: Narcissism as a moderator of the association between feeling under-benefited and irritation
}

\author{
Laurenz L. Meier*1 ${ }^{1}$ and Norbert K. Semmer \\ Department of Psychology, University of Bern, Bern, Switzerland
}

\begin{abstract}
Previous workplace research on narcissists has mainly focused on their performance or their role as leaders. However, little is known about their reaction to work stressors. The current study examined the moderating role of narcissism in the relationship between lack of reciprocity (feeling under-benefited) and irritation. Based on the notion that narcissists have an inflated self-view and a sense of entitlement, we proposed that lack of reciprocity would be positively related to irritation as an indicator of impaired well-being, and that the reaction to lack of reciprocity of those scoring high on narcissism should be particularly strong. We tested these hypotheses in a cross-sectional study with two samples, the first consisting of 106 pilots in the Swiss air force and the second comprising 103 employees in various Swiss organizations. In line with our assumptions, lack of reciprocity was positively related to irritation. Moreover, this relationship was stronger among participants who were high, as compared to low in narcissism. Practical implications of these results are discussed.
\end{abstract}

Keywords: narcissism; lack of reciprocity; equity; fairness; stress; irritation; well-being; work-related stress

\section{Introduction}

Previous workplace research on narcissistic individuals has primarily focused either on their role as a leader, or on their specific behaviours, with findings indicating lower ratings of leadership quality (e.g., Judge, LePine, \& Rich, 2006) and more counterproductive work behaviour (i.e., behaviour that harms organizations and/or people in organizations) for people high on narcissism (Judge et al., 2006; Penney \& Spector, 2002). However, very little is known about the way narcissists react to work stressors. Specifically, it might be assumed that employees with a high level of narcissism are more vulnerable to certain work stressors. In line with this assumption, Penney and Spector (2002) found a stronger association between job constraints and counterproductive work behaviour among people high, as compared to low, in narcissism. However, this effect could not be replicated in a follow-up study (Penney \& Spector, 2003). Therefore, empirical evidence for the hypothesis that narcissists may be more vulnerable to stressors is scarce and inconsistent.

\footnotetext{
*Corresponding author. Email: meierl@usf.edu

${ }^{1}$ Laurenz L. Meier is now at the Department of Psychology, University of South Florida, Tampa, FL, USA.
} 


\section{Reciprocity}

In the present study, we focused on lack of reciprocity as a work stressor. According to the principle of equity (Adams, 1965; other norms are discussed by Deutsch, 1975), people expect that their efforts should be rewarded fairly, and get irritated when this is not the case. Several models in psychology and occupational health deal with this phenomenon (for instance, distributive injustice, e.g., Homans, 1961; lack of reciprocity, e.g., Schaufeli, 2006; effort-reward imbalance, e.g., Siegrist, 2002). The models differ in details, but they all assume that a mismatch between investments and outcomes is stressful. Some emphasize that the ratio between one's investments and outcomes is compared to the ratio of other people (interpersonal comparison, see, for instance, Adams, 1965); others highlight that the ratio is mainly compared to internal standards (intrapersonal comparison; for instance, Schaufeli, 2006). Furthermore, some models assume that receiving too little reward in relationship to contribution, as well as too much is stressful (e.g., Adams, 1965), others only postulate negative effects for being under-benefited (for example, Siegrist, 2002).

Regarding the workplace, models are based on the idea that employees expect their investments concerning the relationships with their supervisors, colleagues, and organization to be reciprocated (see Schaufeli, van Dierendonck, \& van Gorp, 1996). The present study focused on a lack of reciprocity in relation to the organization. Thus, investments (efforts) represent job demands and stressors to be dealt with, duties that are imposed on the employee, and individual effort put into work, whereas rewards consist of salary, esteem, and job security/career opportunities (Siegrist, 2002).

Numerous studies have shown that lack of reciprocity is negatively related to employees' physiological and psychological well-being (Schaufeli, 2006). As noted above, individuals may experience a negative (i.e., feeling under-benefited) or a positive (i.e., feeling over-benefited) lack of reciprocity. However, in general, receiving too little has a stronger impact on well-being than receiving too much (e.g., Taris, Kalimo, \& Schaufeli, 2002). In the present study, we therefore focus on negative lack of reciprocity.

\section{Narcissism}

The construct of narcissism has had a long history in clinical as well as in social psychology (see Morf \& Rhodewalt, 2001), and it is also becoming popular in organizational psychology (Campbell, Hoffman, Campbell, \& Marchisio, 2011). In clinical psychology, narcissism is understood as a personality disorder with clear diagnostic criteria. However, in social and organizational psychology narcissism is conceptualized as a dimension on which everyone can be characterized as having a specific value. From this point of view, individuals differ along a continuum; a recent study supports this perspective (Foster \& Campbell, 2007). Following this, in the current study we understand narcissism as a normal personality trait that differs among people. For brevity, we nevertheless refer to "narcissists" and "nonnarcissists" when talking about people with relatively high versus low narcissism scores.

Narcissism is characterized by a vulnerable and inflated sense of self that is reflected by arrogance, preoccupation with fantasies of success and power, and a need for continuous attention and admiration (see Morf \& Rhodewalt, 2001). 
Moreover, narcissists' self-views are not only high but also unstable and, therefore, fragile (Rhodewalt, Madrian, \& Cheney, 1998). A fragile self-esteem implies high vulnerability. Consequently, negative self-relevant events are likely to be highly threatening; narcissists have to defend their self-esteem, and they tend to do this by reacting to negative feedback and social rejection with comparatively strong anger and aggression (e.g., Twenge \& Campbell, 2003). Given their feelings of grandiosity, sense of entitlement, and expectation of special treatment and privileges, one can assume that they will show especially strong affective reactions when receiving fewer rewards than they believe they deserve. As noted above, the likelihood of an individual evincing a negative reaction to receiving more rewards than they believe they deserve has been suggested in the literature (Adams, 1965), and such an effect has been found in some studies (van Dierendonck, Schaufeli, \& Buunk, 2001) but not in others (Taris et al., 2002). For narcissists, a negative reaction to being overbenefited seems especially unlikely; they have a sense of entitlement that precludes feeling over-benefited, unless the fact that rewards are greater than deserved is absolutely unambiguous and cannot be explained away by one's superiority. Our study therefore focused on feeling under-benefited.

\section{Lack of reciprocity, self-esteem, and narcissism}

A reason why the feeling of being under-benefited may be stressful is the perceived lack of appreciation and respect. In line with this reasoning, Siegrist (2002) noted that an imbalance between effort and reward can have negative consequences by weakening a person's self-esteem and sense of belonging, and such a link between injustice and the feelings of self-esteem and acceptance has been demonstrated empirically (e.g., De Cremer, 2002). These findings support the hypothesis that stressors like lack of reciprocity should represent a threat to self-esteem (see also Semmer, Jacobshagen, Meier, \& Elfering, 2007).

If a threat to self-esteem is, indeed, responsible for the stressful effects of lack of reciprocity, individual differences in reactions to a lack of reciprocity should be related to self-esteem. As noted above, narcissists have a high but fragile self-esteem. Fragility of self-esteem implies that self-esteem is easily threatened, which, in turn, implies that people high in narcissism should be especially sensitive to anything that might threaten their self-esteem, and thus to a perceived lack of esteem or respect. We therefore hypothesize that a lack of reciprocity in terms of under-benefiting is particularly stressful for narcissists, because it poses a threat to their inflated self-view.

What are the typical reactions that narcissists are likely to show when faced with a threat to their self-view? Of course, an individual might accept a negative message about themselves, and this might induce depressed affect. Given the motive for high self-esteem, however, it seems likely that many people would try to ward off the threat, and to attack the source of the threatening message (Tracy \& Robins, 2004). In that case, an irritated, angry reaction would be expected. Given their inflated view of themselves, the likelihood of such reaction seems especially high for narcissists. Indeed, in previous laboratory studies, threats to one's self-view were associated with more aggression and anger among people high, as compared to low, in narcissism (e.g., Twenge \& Campbell, 2003).

Thus, narcissists are likely to react with more irritability when their goal of maintaining an inflated self-view is threatened. Furthermore, such reactions are 
likely to persist over time. Dickerson and Kemeny (2004) showed that socialevaluative stressors are especially likely to induce strong and persistent elevations in cortisol. More generally, Martin and Tesser (1996) state that a persistent threat to a fundamental goal tends to induce rumination. Not surprisingly, therefore, Miller, Pedersen, Earleywine, and Pollock (2003) speculated that narcissism is linked to rumination, particularly after a threat to a narcissist's inflated self-view.

In the organizational stress literature, these two processes - irritability and rumination - have been subsumed under the label of irritation (see Mohr, Müller, Rigotti, Aycan, \& Tschan, 2006). Research has shown that irritation is associated with a variety of stressors, such as time pressure and social stressors (e.g., Garst, Frese, \& Molenaar, 2000). Furthermore, irritation plays an important role in the development of more severe psychological impairments like depression (Dormann \& Zapf, 2002). Irritation therefore strongly suggests itself as a dependent variable.

On the basis of this reasoning, we aimed to test the following two hypotheses:

Hypothesis 1. Lack of reciprocity will be positively related to irritation.

Hypothesis 2. The above relationship will be stronger among participants with high levels of narcissism than among those with low levels of narcissism.

\section{Method}

Two samples were assembled to test our hypotheses. Sample characteristics are described for each sample separately. However, we pooled the two samples for the analyses in order to increase statistical power.

\section{Samples}

\section{Sample 1}

A questionnaire was distributed to pilots of the Swiss air force in the context of a stress and safety survey. Response rate was 56\%. Analyses are based on 106 pilots ( $95 \%$ males). The age of the participants ranged from 22 to 58 years, with an average of 35.3 years $(S D=10.1)$. Twenty-two percent had completed an apprenticeship, $69 \%$ had a completed college education, and $9 \%$ had a university degree. Organizational tenure ranged from one to 36 years; average tenure was 12.1 years $(S D=9.7)$. Most of the participants $(89 \%)$ were employed full-time, and the average level of employment, expressed as percentage of a full-time equivalent, was $96 \%(S D=14 \%)$.

\section{Sample 2}

Sample 1 was somewhat special in that it contained only one type of job (the participants were air force pilots) and was predominantly male. To obtain a more diverse sample of job types and a more equal distribution of males and females, for sample 2 we approached employees of various organizations in Switzerland and asked whether they were willing to fill out a questionnaire assessing organizational well-being. Altogether, four junior research assistants approached 120 employees, of whom 108 agreed to participate. Five participants had to be excluded from the analyses due to missing data. Therefore, the final sample consisted of 103 
participants (50\% males). The sample included white-collar workers (e.g., secretary, accountant; 78\%) as well as blue-collar workers (e.g., metalworker, butcher; 22\%). Age of the participants ranged from 20 to 61 years, with an average of 34.9 years $(S D=11.9)$. Forty-four percent had completed regular school (nine years) or an apprenticeship, 43\% had completed college, and 13\% had a university degree. Organizational tenure ranged from one to 38 years, average being 6.6 years $(S D=8.3)$. The majority of the participants $(60 \%)$ were employed full-time, the average level of employment was $86 \%$ of a full-time equivalent $(S D=21 \%)$.

\section{Measures}

\section{Lack of reciprocity}

Lack of reciprocity was assessed using a scale by vanYperen (1996), adapted by Janssen (2000). This scale assesses the sense of being under-benefited (i.e., obtaining too few rewards relative to one's efforts) but not the sense of being over-benefited (i.e., obtaining too many rewards relative to one's efforts). It consisted of six items (e.g., "I invest more in my job than I receive in return"). Responses were measured on a 7-point scale ranging from 1 (totally disagree) to 7 (totally agree). Internal consistency was good $(\alpha=.89$ for sample $1, \alpha=.87$ for sample $2, \alpha=.88$ for the pooled sample).

\section{Narcissism}

Narcissism was measured using a short version of the Narcissistic Personality Inventory (NPI, Raskin \& Hall, 1979; Schütz, Marcus, \& Sellin, 2004). The original NPI contains true-false statements (Morf \& Rhodewalt, 1993). As in previous research (e.g., Penney \& Spector, 2002), we used a Likert format instead. The scale consisted of 15 items (e.g., "I think that I am someone special"). In sample 1, responses were measured on a 5-point scale ranging from 1 (not at all) to 5 (very much); in sample 2, responses were measured on a 7-point scale ranging from 1 (not at all) to 7 (very much). To pool the samples, the 5-point scale was transformed to a 7-point scale. Internal consistency was good $(\alpha=.86$ for sample $1, \alpha=.92$ for sample $2, \alpha=.90$ for the pooled sample).

\section{Irritation}

Irritation was assessed with a scale by Mohr (Mohr et al., 2006). It consists of eight items (e.g., "If other people talk to me, I often react grumpily"; "Even at home I often think of my problems at work"). Responses were measured on a 7-point scale ranging from 1 (strongly disagree) to 7 (strongly agree). Internal consistency was good ( $\alpha=.89$ for sample $1, \alpha=.90$ for sample $2, \alpha=.89$ for the pooled sample).

\section{Control variables}

Previous research found irritation to be related to age (Mohr, Rigotti, \& Müller, 2005), level of employment (Jacobshagen, Amstad, Semmer, \& Kuster, 2005), gender, and education (Bernhard-Oettel, Isaksson, \& Bellaagh, 2008); lack of reciprocity has 
Table 1. Descriptive statistics and correlations among the study variables.

\begin{tabular}{|c|c|c|c|c|c|c|c|c|}
\hline Variables & $M$ & $S D$ & 1 & 2 & 3 & 4 & 5 & 6 \\
\hline 1. Gender ${ }^{\mathrm{a}}$ & 0.73 & - & - & & & & & \\
\hline 2. Age & 35.08 & 10.98 & .18 & - & & & & \\
\hline 3. Education ${ }^{\mathrm{b}}$ & - & - & .08 & .08 & - & & & \\
\hline 4. Level of employment & 91.22 & 18.96 & $.21^{*}$ & .08 & .03 & - & & \\
\hline 5. Lack of reciprocity & 2.97 & 1.18 & .02 & .04 & .00 & .04 & - & \\
\hline 6. Narcissism & 3.62 & 0.99 & .06 & .10 & $.20^{*}$ & .08 & .05 & - \\
\hline 7. Irritation & 2.62 & 1.10 & $.15^{*}$ & $.20^{*}$ & $.13^{\dagger}$ & .06 & $.46^{*}$ & $.12^{\dagger}$ \\
\hline
\end{tabular}

Notes: $N=209 ;{ }^{\mathrm{a}} 0=$ female, $1=$ male; ${ }^{\mathrm{b}}$ Education is an ordinal variable, therefore, Spearman Rho correlations have been computed. In the regression analyses we used a dummy coding for education. ${ }^{\dagger} p<.10 ;{ }^{*} p<.05$.

been related to gender (Janssen, 2000), education (Taris et al., 2002), and level of employment (Semmer, Tschan, Meier, Facchin, \& Jacobshagen, 2010); and narcissism has been be related to age and gender (Foster, Campbell, \& Twenge, 2003). We therefore controlled for age, gender, education, and level of employment.

\section{Results}

Table 1 shows the means, standard deviations, and zero-order correlations of all study variables. We conducted a hierarchical regression analysis to test our hypotheses with the pooled sample, centring predictor variables around their grand mean in order to facilitate the interpretation of main effects in models containing interaction terms (see Aiken \& West, 1991). Predictors were entered in the following steps: (1) gender, age, education, and level of employment as control variables; (2) lack of reciprocity, and narcissism, and, (3) the interaction between lack of

Table 2. Summary of hierarchical regression analysis predicting irritation.

\begin{tabular}{|c|c|c|c|c|c|c|c|c|c|}
\hline & \multicolumn{3}{|c|}{ Step 1} & \multicolumn{3}{|c|}{ Step 2} & \multicolumn{3}{|c|}{ Step 3} \\
\hline & $B$ & $S E$ of $B$ & $\beta$ & $B$ & $S E$ of $B$ & $\beta$ & $B$ & $S E$ of $B$ & $\beta$ \\
\hline \multicolumn{10}{|l|}{ Step 1} \\
\hline Gender $^{\mathrm{a}}$ & 0.25 & 0.18 & .10 & 0.22 & 0.16 & .09 & 0.27 & 0.15 & $.11^{\dagger}$ \\
\hline Age & 0.02 & 0.01 & $.17 *$ & 0.02 & 0.01 & $.17 *$ & 0.01 & 0.01 & $.14 *$ \\
\hline Education dummy 1 & 0.09 & 0.17 & .04 & 0.10 & 0.15 & .04 & 0.11 & 0.15 & .05 \\
\hline Education dummy 2 & 0.35 & 0.26 & .10 & 0.35 & 0.23 & .10 & 0.40 & 0.22 & .12 \\
\hline Level of employment & 0.00 & 0.00 & .02 & 0.00 & 0.00 & .01 & 0.00 & 0.00 & .00 \\
\hline \multicolumn{10}{|l|}{ Step 2} \\
\hline Lack of reciprocity & & & & 0.42 & 0.06 & $.45^{*}$ & 0.42 & 0.06 & $.45^{*}$ \\
\hline Narcissism & & & & 0.11 & 0.07 & .10 & 0.15 & 0.07 & $.13^{*}$ \\
\hline \multicolumn{10}{|l|}{ Step 3} \\
\hline $\begin{array}{l}\text { Lack of } \\
\quad \text { reciprocity } \times \text { Narcissism }\end{array}$ & & & & & & & 0.24 & 0.06 & $.23 *$ \\
\hline
\end{tabular}

Notes: ${ }^{\mathrm{a}} 0=$ female, $1=$ male.

$R^{2}=.06(p<.05)$ for Step $1 ; \Delta R^{2}=.21(p<.05)$ for Step $2 ; \Delta R^{2}=.05(p<.05)$ for Step 3.

${ }^{\dagger} p<.10 ; * p<.05$. 

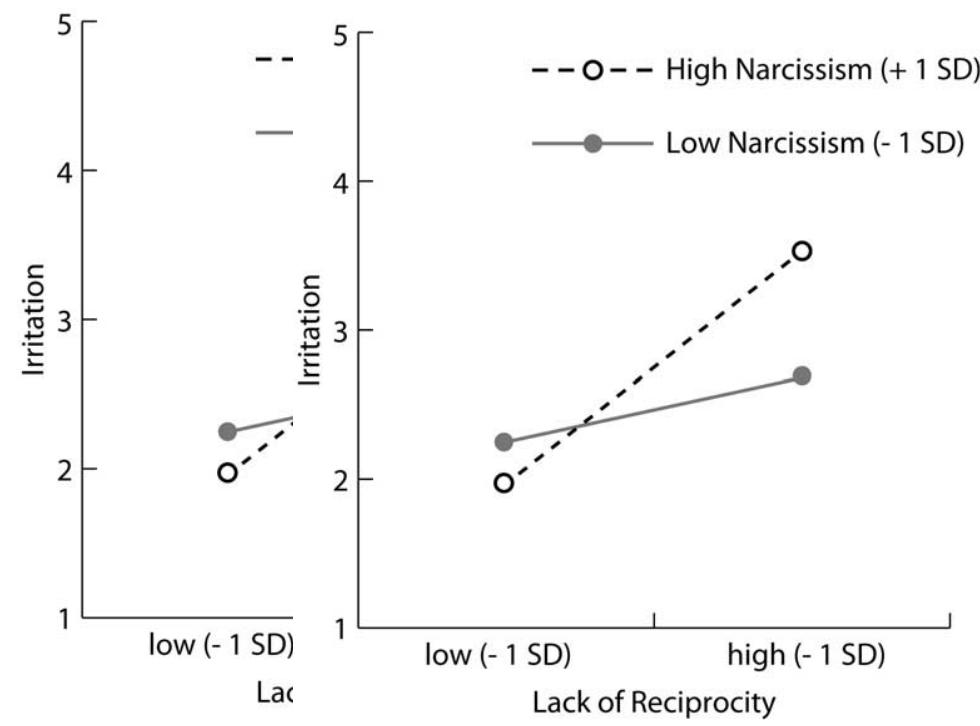

Figure 1. Interaction between lack of reciprocity and narcissism, predicting irritation.

reciprocity and narcissism. Since we used the pooled sample, we tested whether including sample type as a dummy variable would influence our results. However, controlling for sample type yielded no effects, neither in terms of a main effect nor in terms of interactions with the other predictors. Moreover, including sample type as a control variable did not change the effects of the other predictors. Therefore, sample type was omitted from the final analysis, which is shown in Table 2.

In line with our first hypothesis, lack of reciprocity was found to be associated with irritation $(\beta=.45, p<.05)$, over and above the control variables. However, this main effect was qualified by the proposed interaction between lack of reciprocity and narcissism $(\beta=.23, p<.05)$, explaining an additional $5 \%$ of variance $\left(f^{2}=.08\right)$. In line with our second hypothesis, lack of reciprocity was more strongly related to irritation among people with high levels of narcissism $(B=0.66, p<.05)$ as compared with participants with low levels of narcissism $(B=0.16, p<.05)$. The pattern is presented in Figure 1, which shows the regression lines for participants with values $1 S D$ above and below the mean, respectively (Aiken \& West, 1991).

Additional analyses with the two samples separately yielded very similar results. Specifically, the main effect of lack of reciprocity was significant (Sample 1: $\beta=.52$, Sample 2: $\beta=.34$; both $p \mathrm{~s}<.05$ ) and was qualified by the interaction between lack of reciprocity and narcissism in both samples (Sample 1: $\beta=.24$, Sample 2: $\beta=.21$; both $p \mathrm{~s}<.05)$.

\section{Discussion}

This study examined whether narcissism moderates the association between lack of reciprocity and irritation. We proposed that a lack of reciprocity is a strong threat to narcissists' sense of entitlement and inflated self-view and hence, lack of reciprocity should be more strongly related to irritation among narcissists. 
In accordance with our hypothesis, lack of reciprocity was more strongly related to irritation among participants high on narcissism than among participants low on narcissism. This result is in line with our reasoning that narcissists are especially sensitive to threats to their self-esteem, because their self-esteem is fragile. As perceiving that one's effort is not reciprocated appropriately may constitute a threat to self-esteem, narcissists should react with especially strong irritation if they perceive that their effort is not reciprocated. These results complement previous research, indicating that narcissists react with more anger (e.g., Twenge \& Campbell, 2003) and more counterproductive behaviour (Penney \& Spector, 2002) to an obstruction of an important goal. To the best of our knowledge, this is the first study to show that narcissists' well-being is related to adverse work conditions in terms of lack of reciprocity.

Interestingly, people high on narcissism did not perceive more lack of reciprocity in general, compared to people low on narcissism, as indicated by the non-significant correlations between narcissism and lack of reciprocity. Thus, overall, narcissists did not feel that they had a worse deal than non-narcissists. This finding contradicts the result of a previous study, which found that people high in narcissism report higher interpersonal transgression (e.g., failure to be appreciated adequately) than people low on narcissism (McCullough, Emmons, Kilpatrick, \& Mooney, 2003). However, a pattern similar to the one found in the current paper was reported in a study on the effect of perceived unfairness of supervisors' behaviour among employees with high but unstable self-esteem (Meier, Semmer, \& Hupfeld, 2009). Similarly to narcissists, people with high but unstable self-esteem have positive self-feelings that are fragile and need continual validation (cf. Rhodewalt et al., 1998). Employees with high but unstable self-esteem did not perceive their supervisor's behaviour to be more unfair than employees with a high and stable self-esteem. However, they reacted most strongly to unfair treatment (Meier et al., 2009). Thus, the effect of narcissism or a high but unstable self-esteem seems to lie in a higher vulnerability to an imbalance or unfairness, rather than in a general feeling of not being treated adequately.

Our results show that personality has an impact on the relationship between lack of reciprocity and irritation, indicated by an additional $5 \%$ of variance that is explained by the interaction between lack or reciprocity and narcissism. Compared to the interaction effects typically found in field research, this is a rather large amount of additionally explained variance (e.g., Champoux \& Peters, 1987). However, this should not overshadow the fact that lack of reciprocity was strongly related to irritation in general, as indicated by a zero-order correlation of almost .5. Thus, lack of reciprocity seems to be a significant threat to well-being in general. This result is in line with the assumption that lack of reciprocity may threaten one's selfesteem (e.g., Siegrist, 2002) and that threats to self-esteem are particularly stressful (Semmer et al., 2007).

\section{Limitations}

A number of limitations concerning the current study need to be acknowledged. First, the cross-sectional nature of the data does not allow any clear inference of a cause-effect relationship. On the other hand, the interaction mechanism we hypothesized, and found, is quite specific and not easily explained by a third factor or any kind of reversed causation. Second, as the study was based on self-report 
data, one could question whether the size of the relationships may be overestimated, due to common method variance (Semmer, Grebner, \& Elfering, 2004). However, common method variance tends to render detecting interaction effects in moderated regression, which is inherently conservative already (McClelland \& Judd, 1993), even more difficult (Aiken \& West, 1991). Common method variance is therefore not likely to explain our results.

\section{Directions for further research}

To address the question of causal inferences, we suggest that future studies use longitudinal designs. Also, diary studies that focus on intraindividual changes in reciprocity and well-being would be desirable. Future research may also seek to identify additional job characteristics, besides lack of reciprocity that could be particularly stressful for narcissists. As noted, narcissists have an inflated and fragile

self-esteem that is easily threatened. Several work characteristics have been identified as relevant to employees' self-esteem. To note only a few, previous research has indicated that self-esteem can be threatened by abusive supervisors (Burton \& Hoobler, 2006), or stressful situations, that are perceived as illegitimate (Semmer et al., 2007). Therefore, future research may wish to examine whether these stressors have a stronger negative impact on well-being among people high in narcissism than among those low in narcissism.

The present study only examined the way narcissists react to the experience of disadvantage, but not how they react to preferential treatment. As mentioned above, equity theory (Adams, 1965) and some empirical findings (e.g., van Dierendonck et al., 2001) suggest that the feeling of being over-benefited may also be stressful. Other studies, however, found that employees who felt that their rewards exceeded their investments, showed similar well-being to those who experienced a balance between their rewards and investments (e.g., Taris et al., 2002). Given narcissists' feelings of grandiosity and entitlement, it is reasonable to assume that they would have difficulty in interpreting a high level of rewards as over-reward. Future research may therefore consider the role of narcissism or entitlement (Campbell, Bonacci, Shelton, Exline, \& Bushman, 2004) in more detail in equity research.

\section{Practical implications}

Our results are in line with previous research (e.g., Schaufeli, 2006, Siegrist, 2002), demonstrating that a perceived lack of reciprocity is strongly related to irritation, which has been found to be a risk factor for the onset of depression (Dormann \& Zapf, 2002). Therefore, organizations should strive for appropriate reciprocation of employee efforts. As reduction of effort is often not a feasible strategy, supervisors could focus on rewards. Showing appreciation would be especially important, as esteem seems to be the most important type of reward (van Vegchel, de Jonge, Bakker, \& Schaufeli, 2002). However, not everyone reacts to an imbalance in a similar manner. For employees with strong narcissistic characteristics, feeling underbenefited is particularly related to impaired well-being. Thus, one should not mistake the self-assured self-presentation of narcissists as an indicator of a secure self-esteem. Narcissists need more appreciation than one might assume; and if they do not receive the appreciation they expect, they may react aggressively (e.g., Twenge \& Campbell, 
2003) and with impaired well-being. To the extent, however, that their quest for appreciation and other rewards is excessive, supervisors may find it difficult to satisfy this need, as this may be associated with creating inequity for other employees.

\section{Acknowledgements}

The authors wish to thank Matthias Bucher, Martial Berset, Ruth Häusler, Aurélie Urwyler, Andrea Huber, Claudia Portmann, and Carmen Prevost for their help during the data collection and Paul E. Spector for his helpful comments on this paper.

\section{References}

Adams, J.S. (1965). Inequity in social exchange. In L. Berkowitz (Ed.), Advances in experimental social psychology (Vol. 2) (pp. 267-299). New York: Academic.

Aiken, L.S., \& West, S.G. (1991). Multiple regression: Testing and interpreting Interactions. Newbury Park, CA: Sage.

Bernhard-Oettel, C., Isaksson, K., \& Bellaagh, K. (2008). Patterns of contract motives and work involvement in temporary work: Relationships to work-related and general well-being. Economic and Industrial Democracy, 29, 565-591.

Burton, J.P., \& Hoobler, J.M. (2006). Subordinate self-esteem and abusive supervision. Journal of Managerial Issues, 18, 340-355.

Campbell, W.K., Bonacci, A.M., Shelton, J., Exline, J.J., \& Bushman, B.J. (2004). Psychological entitlement: Interpersonal consequences and validation of a self-report measure. Journal of Personality Assessment, 83, 29-45.

Campbell, W.K., Hoffman, B.J., Campbell, S.M., \& Marchisio, G. (2011). Narcissism in organizational contexts. Human Resource Management Review, 21, 268-284.

Champoux, J.E., \& Peters, W. (1987). Form, effect size, and power in moderated regression analysis. Journal of Occupational Psychology, 60, 243-255.

De Cremer, D. (2002). The self-relevant implications of distribution rules: When self-esteem and acceptance are influenced by violations of the equity rule. Social Justice Research, 15, 327-339.

Deutsch, M. (1975). Equity, equality, and need: What determines which value will be used as the basis of distributive justice? Journal of Social Issues, 31, 137-149.

Dickerson, S.S., \& Kemeny, M.E. (2004). Acute stressors and cortisol responses: A theoretical integration and synthesis of laboratory research. Psychological Bulletin, 130, 335-391.

Dormann, C., \& Zapf, D. (2002). Social stressors at work, irritation, and depressive symptoms: Accounting for unmeasured third variables in a multi-wave study. Journal of Occupational and Organizational Psychology, 75, 33-58.

Foster, J.D., \& Campbell, W.K. (2007). Are there such things as "Narcissists" in social psychology? A taxometric analysis of the Narcissistic Personality Inventory. Personality and Individual Differences, 43, 1321-1332.

Foster, J.D., Campbell, J.D., \& Twenge, J.M. (2003). Individual differences in narcissism: Inflated self-views across the lifespan and around the world. Journal of Research in Personality, 37(6), 469-486.

Garst, H., Frese, M., \& Molenaar, P.C.M. (2000). The temporal factor of change in stressorstrain relationships: A growth curve model on a longitudinal study in East Germany. Journal of Applied Psychology, 85, 417-438.

Homans, G.C. (1961). Social behavior: Its elementary forms. New York: Harcourt Brace Jovanovich.

Jacobshagen, N., Amstad, F.T., Semmer, N.K., \& Kuster, M. (2005). Work-Family-Balance im Topmanagement: Konflikt zwischen Arbeit und Familie als Mediator der Beziehung zwischen Stressoren und Befinden [Work-family balance at the top management level: 
Work-family conflict as a mediator of the relationship between stressors and strain]. Zeitschrift für Arbeits- und Organisationspsychologie, 49, 208-219.

Janssen, O. (2000). Job demands, perceptions of effort-reward fairness and innovative work behaviour. Journal of Occupational and Organizational Psychology, 73, 287-302.

Judge, T.A., LePine, J.A., \& Rich, B.L. (2006). Loving yourself abundantly: Relationship of the narcissistic personality to self- and other perceptions of workplace deviance, leadership, and task and contextual performance. Journal of Applied Psychology, 91, 762-776.

Martin, L.L., \& Tesser, A. (1996). Some ruminative thoughts. In R.S. Wyer (Ed.), Ruminative thoughts (pp. 1-47). Mahwah, NJ: Erlbaum.

McClelland, G.H., \& Judd, C.M. (1993). Statistical difficulties of detecting interactions and moderator effects. Psychological Bulletin, 114, 376-390.

McCullough, M.E., Emmons, R.A., Kilpatrick, S.D., \& Mooney, C.N. (2003). Narcissists as "victims": The role of narcissism in the perception of transgressions. Personality and Social Psychology Bulletin, 29, 885-893.

Meier, L.L., Semmer, N.K., \& Hupfeld, J. (2009). The impact of unfair treatment on depressive mood: The moderating role of self-esteem level and self-esteem instability. Personality and Social Psychology Bulletin, 35, 643-655.

Miller, N., Pedersen, W.C., Earleywine, M., \& Pollock, V.E. (2003). A theoretical model of triggered displaced aggression. Personality and Social Psychology Review, 7, 75-97.

Mohr, G., Müller, A., Rigotti, T., Aycan, Z., \& Tschan, F. (2006). The assessment of psychological strain in work contexts: Concerning the structural equivalency of nine language adaptations of the Irritation scale. European Journal of Psychological Assessment, 22(3), 198-206.

Mohr, G., Rigotti, T., \& Müller, A. (2005). Irritation-ein Instrument zur Erfassung psychischer Beanspruchung im Arbeitskontext. Skalen- und Itemparameter aus 15 Studien. [Irritationan instrument assessing mental strain in working contexts. Scale and item parameters from 15 studies]. Zeitschrift für Arbeits- und Organisationspsychologie, 49, 44-48.

Morf, C.C., \& Rhodewalt, F. (1993). Narcissism and self-evaluation maintenance: Explorations in object relations. Personality and Social Psychology Bulletin, 19, 668-676.

Morf, C.C., \& Rhodewalt, F. (2001). Unraveling the paradoxes of narcissism: A dynamic selfregulatory processing model. Psychological Inquiry, 12, 177-196.

Penney, L.M., \& Spector, P.E. (2002). Narcissism and counterproductive work behavior: Do bigger egos mean bigger problems? International Journal of Selection and Assessment, 10, 126-134.

Penney, L.M., \& Spector, P.E. (2003, April). Workplace incivility and counterproductive workplace behavior. Paper presented at the meeting of the Society for Industrial and Organizational Psychology, Orlando, FL.

Raskin, R.N., \& Hall, C.S. (1979). A narcissistic personality inventory. Psychological Reports, 45, 590 .

Rhodewalt, F., Madrian, J.C., \& Cheney, S. (1998). Narcissism, self-knowledge organization, and emotional reactivity: The effect of daily experiences on self-esteem and affect. Personality and Social Psychology Bulletin, 24, 75-87.

Schaufeli, W.B. (2006). The balance of give and take: Toward a social exchange model of burnout. International Review of Social Psychology, 19, 87-131.

Schaufeli, W., van Dierendonck, D., \& van Gorp, K. (1996). Burnout and reciprocity: Towards a dual-level social exchange model. Work \& Stress, 10, 225-237.

Schütz, A., Marcus, B., \& Sellin, I. (2004). Die Messung von Narzissmus als Personlichkeitskonstrukt: Psychometrische Eigenschaften einer Lang- und einer Kurzform des Deutschen NPI (Narcissistic Personality Inventory) [Measuring narcissism as a personality construct: Psychometric properties of a long and a short version of the German Narcissistic Personality Inventory]. Diagnostica, 50, 202-218.

Semmer, N.K., Grebner, S., \& Elfering, A. (2004). Beyond self-report: Using observational, physiological, and event-based measures in research on occupational stress. In P.L. Perrewe \& D.C. Ganster (Eds.), Emotional and physiological processes and positive intervention 
strategies. Research in occupational stress and well-being (Vol. 3) (pp. 205-263). Amsterdam: JAI.

Semmer, N.K., Jacobshagen, N., Meier, L.L., \& Elfering, A. (2007). Occupational stress research: The "Stress-as-Offense-to-Self" perspective. In J. Houdmont \& S. McIntyre (Eds.), Occupational health psychology: European perspectives on research, education and practice (Vol. 2, Avioso S. Pedro, Portugal: ISMAI.

Semmer, N.K., Tschan, F., Meier, L.L., Facchin, S., \& Jacobshagen, N. (2010). Illegitimate tasks and counterproductive work behavior. Applied Psychology: An International Review, 59, 70-96.

Siegrist, J. (2002). Effort-reward imbalance at work and health. In P.L. Perrewé \& D.C. Ganster (Eds.), Historical and current perspectives on stress and health (Vol. 2) (pp. 261-291). New York: JAI Elsevier.

Taris, T.W., Kalimo, R., \& Schaufeli, W.B. (2002). Inequity at work: Its measurement and association with worker health. Work \& Stress, 16, 287-301.

Tracy, J.L., \& Robins, R.W. (2004). Putting the self into self-conscious emotions: A theoretical model. Psychological Inquiry, 15, 103-125.

Twenge, J.M., \& Campbell, W.K. (2003). Isn't it fun to get the respect that we're going to deserve?" Narcissism, social rejection, and aggression. Personality and Social Psychology Bulletin, 29, 261-272.

van Dierendonck, D., Schaufeli, W.B., \& Buunk, B.P. (2001). Burnout and inequity among human service professionals: A longitudinal study. Journal of Occupational Health Psychology, 6, 43-52.

van Vegchel, N., de Jonge, J., Bakker, A.B., \& Schaufeli, W.B. (2002). Testing global and specific indicators of rewards in the Effort-Reward Imbalance Model: Does it make any difference? European Journal of Work \& Organizational Psychology, 11, 403-421.

vanYperen, N.W. (1996). Communal orientation and the burnout syndrome among nurses: A replication and extension. Journal of Applied Social Psychology, 26, 338-354. 